\title{
Time Meter Estimation Technique For Naval Equipment
}

\author{
Stephen R. Luke; Naval Undersea Warfare Center Detachment, Norfolk \\ Rajesh M. Sutariya; Naval Undersea Warfare Center Detachment, Norfolk
}

Key Words: Regression Analysis, Time Estimation, MTBF Calculation, Readiness, Wilcoxon Analysis

\section{SUMMARY \& CONCLUSIONS}

System reliability is analyzed in terms of Mean Time Between Failure (MTBF) and its inverse, failure rate. Currently, for the AN/SQQ-28(V), the calculation for MTBF is achieved by dividing some estimated operating time by number of failures. Operating time is usually estimated by ship's steaming hours or some fraction thereof. This paper proves that there is no statistically sound reason for using such an estimation and provides an alternate method for obtaining a more credible estimate.

Optimally, actual time meter readings should be used. Unfortunately, most Naval equipment does not require regular reporting of time meter readings. When it is required, there are gaps in reporting of time meter readings. Lack of time meter readings makes it difficult to calculate system reliability. This paper describes a method to estimate operating time using existing time meter readings by calculating duty factors for each unit in the system. The duty factor is used with Reliability Block Diagram database which gives configuration for each hull and failure database (i. e. Logistics Support Center Failure database and the 3-M database) to calculate the failure rates and MTBFs for parts, units and systems.

The method used for estimating time meter readings identifies the percentage of time which particular systems are used. Percentage of time used is tested in a regression analysis to show the relationship between usage and the number of failures per year. This paper shows that there is no statistical relationship between total number of failures per year and the percentage of time a system is on. More research is needed to make operational decisions on systems (ie. whether to leave the system energized or off when not in use).

This paper presents both a better estimate for operational time and a method for drawing better conclusions from reliability data using regression analysis. Estimation is a hybrid of known operational time and unknown time estimation using an order statistics median estimation. Results of this paper can be extended to other systems as long as care is taken to use statistics properly.

\section{INTRODUCTION}

In this paper, common assumptions are explored which are used to estimate operating time in Naval Equipments.
Since actual time is often not available, an estimate is normally created using an estimate of the percentage of time a particular system is energized with respect to the Ship's Engine. Section 1 shows statistically why this is an unreasonable approach when the system in question is not operationally tied to the Ship's engine.

Although for many systems there is a requirement to take monthly time meter readings, these readings are often erroneous, confusing and incomplete. Section 3 describes the problems encountered using actual time. Because of the problems with collecting actual time data, many agencies resort to a steaming hour estimation even when actual time data is available. Section 4 proposes a statistically sound estimation of time meter readings when there is time meter data which is incomplete.

While constructing the model to compute system MTBF, it was discovered that there was a helpful side benefit in knowing the percentage of time each system is energized. Section 5 presents a practical application which can be derived from the proposed model showing a relationship between operating philosophy and failures per year.

\subsection{Acronyms}

AN/SQQ-28(V)

Sonar Signal Processing System, comprised of:

AN/USH-32(V) Signal Data Recorder/Reproducer Set

AN/UYK-20AX(V) Data Processing Set

AN/USQ-69(V) Data Terminal Set

AN/UYS-1(V) Spectrum Analyzer

TD-1307 Time Code Control Unit (TCCU)

SA-2359 Interface Signal Switching Unit (ISSU)

ETM Elapsed Time Meter

ISEA In Service Engineering Agent

MRC Maintenance Requirement Card

MTBF Mean Time Between Failures

3-M Maintenance Material Management

\subsection{Assumptions}

* AN/SQQ-28(V) is an electronic system with constant failure rate during the useful life

* Operation of AN/SQQ-28(V) is independent of operation of ship's engines

US Government work not protected by US copyright 


\subsection{Notation}

$\beta_{0} \quad$ Y-intercept, used in regression analyses

$\beta_{1}, \beta_{2}, \beta_{3} \quad$ Unknown coefficients used in regression analyses

s-Confidence

An interval with upper and lower limits

Interval

that measures the uncertainty in knowing the true value of a statistical parameter.

Regression

Analysis

A statistical technique for estimating the parameters of an equation relating a particular variable to a set of variables ("least squares" or "curve fitting")

$\mathbf{X}_{\mathrm{ei}}$

$\mathbf{F}$

$\mathbf{X}_{\mathrm{shm}}$

$\mathbf{X}_{\text {ster }}$

Wilcoxon Test

Cold Iron Hours: number of hours in a given period of time in which a ship's engines are off

F statistic which is an indication of how close the estimate can predict known data

Steaming Hours Not Underway: number of hours in a given period of time in which a ship's engines are on and the ship is not underway

Steaming Hours Underway: number of hours in a given period of time in which ship's engines are on and the ship is underway

Tests a median from an ordered set of data points of unknown distribution with certain s-confidence

\section{STEAMING HOUR ESTIMATION}

\section{The Present Method and Its Problems:}

Since time meter readings have historically been unavailable, most reliability calculations use an estimate of equipment operational time in the calculation of MTBF based upon the amount of time the Ship's Engine is on with respect to total time. Total time can be subdivided with respect to Ship's engine operating time as follows:

1) Steaming Hours Underway $\left(x_{s t w}\right)$ - Number of hours in a given period of time in which the ship's engines are on and the ship is underway.

2) Steaming Hours Not Underway $\left(\mathrm{x}_{\text {stmu }}\right)$ - Number of hours in a given period of time in which the ship's engines are on and the ship is not underway.
3) Cold Iron Hours $\left(x_{c i}\right)$ - Number of hours in a given period of time in which the ship's engines are off.

Hence, the equation (1) can be written:

$$
x_{\text {shu }}+x_{\text {shau }}+x_{c i}=\text { total time }
$$

Basically, there are two ways to estimate the amount of time a piece of equipment is operational with respect to the ship's engine:

1) Use an educated estimate, provided by some system expert, of a percentage of Ships' Steaming Hours which will yield equipment operational time. Usually, this is expressed as a percentage of Steaming hours underway only. Occasionally, it is expressed as a fraction of all three of the above factors.

2) Perform a regression analysis of actual time meter readings, estimating actual time with the three factors of ship's engine operating time. This is the same as above except the values are derived from actual data statistically instead of subjectively from someone's opinion. It is preferred because it is data driven and therefore more objective.

It should be noted that, no matter what estimation technique is used to estimate operating hours with engine hours, the basic underlying assumption is that the decision to operate the equipment in question is related to the ship's engines. Equipment considered in this paper can be operated without the ship's engine energized. Conclusions from this paper do not necessarily apply to other systems which have a stronger relationship to ship's engines.

The authors, as the In Service Engineering Agents (ISEA) for the AN/SQQ-28, have been asked on several occasions for "system expertise estimates" (Method 1). The problem with this approach is that it is far too subjective to yield credible data. Also, there is some confusion as to what is being estimated since the system expert believes he is giving his professional estimation of what percentage of time the system in question is operational, not the percentage of time the system is operational with respect to the ship's engines.

As stated earlier, method 2 is more objective than method 1 because it is data-driven. To the best of the authors' knowledge, method 2 has never been used before. One side benefit of method 2 is that the statistical significance of the estimate can be evaluated.

Examining Method 2 further, the equations (2) and (3) are implied:

1) Operating Time $=\beta_{0}+\beta_{1}\left(X_{c h a n}\right)+\beta_{2}\left(X_{c m m}\right)+\beta_{3}\left(X_{s i}\right)$

2) $X_{\text {dim }}+X_{\text {sid }}+X_{\text {ef }}=$ Total Calendar Time

Where:

$\beta_{0}-y$-intercept

$\beta_{1}$ - Coefficient of Steaming Hours Underway equipment is on. 
$\beta_{2}$ - Coefficient of Steaming Hours Not Underway equipment is on. $\beta_{3}$ - Coefficient of Cold Iron Hours equipment is on.

A regression analysis was performed on six equipments and fifteen hulls. Note that it is the objective of a regression analysis to obtain the mathematical equation which best approximates empirical data and to determine whether the approximation obtained follows empirical data well enough to be deemed credible. Equipments chosen are all part of the AN/SQQ-28(V) system found on FFG 7, DD 963, and CG 47 class hulls. TABLE 1 gives a synopsis of the results which led to the conclusion that steaming hours cannot be used to credibly approximate operating time.

TABLE 1.

\begin{tabular}{|c|c|c|c|c|c|c|}
\hline Equipment & $\beta_{0}$ & $\beta_{1}$ & $\beta_{3}$ & $\beta_{3}$ & $F^{*}$ & Aocopt/Reject \\
\hline AN/USQ-69,V) & 1727 & -1.67 & 2.31 & 0.18 & 10.82 & Reject' \\
\hline ANTUYS-1(V) & 707 & 1.39 & -1.21 & 0.17 & 38.86 & Rejeat \\
\hline AN/OYK-20AX(V) & 1510 & -0.53 & 0.74 & 0.18 & 7.36 & Rojow' \\
\hline AN/USH-32CV & 385 & 0.15 & 0.17 & 0.086 & 0.86 & Reject ${ }^{2}$ \\
\hline TD-1307 (TCCU) & 676 & 1.34 & -1.28 & -0.03 & 6.03 & Rejeot \\
\hline SA-2359 (ISSU) & 1412 & 0.065 & 1.25 & 0.11 & 28.64 & Rejoot \\
\hline
\end{tabular}

REGRESSION DATA FOR AN/SQQ-28 OPERATING TIME AS A FUNCTION OF STEAMING HOURS

1.

${ }^{1}$ Reject as impractical since $\beta_{1,2, \text { or } 3}$ is not between 0 and

${ }^{2}$ Reject Statistically at $99 \%$ s-Confidence.

* $\mathrm{F}$ is the $\mathrm{F}$ statistic which is an indication of how close the estimate can predict known data ("goodness of fit"). For a 3 factor regression, with 15 samples, reject the hypothesis that regression exists if:

$$
F<F_{(998)}^{(3,41)}=4.301
$$

Furthermore, it is usually assumed that :

$$
0 \leq \beta_{1} \leq 1 ; 0 \leq \beta_{2} \leq 1 ; 0 \leq \beta_{3} \leq 1
$$

Because:

If $\beta_{i}$ 's are negative, it is possible for a given set of steaming hour readings to obtain a negative operating time estimate. If $\beta_{i}$ 's are greater than 1 , it is possible for a given set of steaming hour readings to obtain an operating time estimate which exceeds calendar time. There is nothing in the calculation of regression equation (2) to constrain $\beta_{i}$ 's to values between zero and one. Intuitively, results from the regression analysis for the AN/USQ-69(V), the AN/UYS-1, the AN/UYK-20AX(V), the TCCU and the ISSU are deemed impractical because they yield unacceptable results.

Therefore, the data reviewed leads to the conclusion that for five of the six equipments in question, there appears to be no relation between Ships' Steaming hours and operation of the equipment for both practical reasons $\left(\beta_{i}\right.$ negative or greater than 1). For one equipment, the AN/USH-32, there is no statistical relationship ( $F$ is less than 4.301).

Since Steaming Hours does not provide a good estimate of Operational hours, another method was devised to estimate operational hours. The method used to perform a multiple regression analysis can be found in reference [1], pages 23.108 through 23.115 .

\section{ACTUAL TIME PROBLEMS}

\section{The Optimal Method and Why It Cannot be Used:}

In the Navy, regular scheduled maintenance is scheduled via Maintenance Requirement Cards (MRCs). By MRC EXX1 (ref [3]), Ship's Force is required to take monthly time meter readings on the AN/SQQ-28(V). Records of subject monthly time meter readings are recorded by ship's force on OPNAV 4790/2K Ship's Maintenance forms then placed into a central database through the National Institute of Health's "3-M" system.

Because of the size of the 3-M database, time meter records are very difficult to retrieve. Also, there appears to be a lack of consistency in the way in which records are placed in the 3-M system. Because of these types of problems, it can be time consuming and a little tricky to find all the monthly records. As a result, a number of special searches are performed on the data to find the readings in question. The problems with reporting are only temporary, however, because the ISEA has already initiated changes to the subject MRC card to standardize reporting techniques. Until the standardized method is implemented by the fleet, it is necessary to use an approximation for time meter readings which are not available.

Even properly reported time meter readings have to be taken with a grain of interpretation. Sometimes two subsequent time meter readings show what appear to be the meter rolling backwards. This could have several possible distinct causes:

a) The meter may have been replaced since the last reading.

b) The meter may have "rolled over" (passed 9999).

c) The reading may fail to report a decimal point in one reading making it appear anomalous (ie. reading $1=$ 19062 , reading $2=2051.1$, reading $3=2188.5$, etc reading 1 is missing a decimal point).

d) The wrong meter may be reported in one of the readings

e) The reading could be wrong for some other reason.

As a result of the reasons outlined above, it was decided not to use any automatic calculation directly from 3-M to estimate elapsed time. Instead, time meter readings were transcribed into an ORACLE database and analysis was performed using the ORACLE database. 


\section{ACTUAL TIME ESTIMATION}

A Proposal for a Better Estimate of Operating Time using Available Data:

Each time meter reading in the database is associated with a particular hull, subsystem, unit and time meter serial number. For every record, there are associated pairs of date and time meter readings recorded. For example, the readings on the hull CG 56, system- AN/SQQ-89(V), subsystemAN/SQQ-28(V)3, unit SA-2359 (Unit 301 ISSU), time meter serial number C23, are given in TABLE 2.

TABLE 2.

\begin{tabular}{|l|l|l|l|l|l|l|l||}
\hline Hull & Unil No. & $\begin{array}{l}\text { Ser } \\
\text { No. }\end{array}$ & Dale & Meter & $\begin{array}{l}\text { Diff. in } \\
\text { Dale }\end{array}$ & $\begin{array}{l}\text { \% Used } \\
\text { in PD. }\end{array}$ & $\begin{array}{l}\text { Acoept } \\
\text { Rejoct }\end{array}$ \\
\hline CG 56 & 301 ISSU & C23 & 01-JUL-87 & 220.2 & & & \\
\hline & & & O1-JAN-90 & 221.7 & 915 & $0.0068 \%$ & Reject \\
\hline & & & 01-FEB-90 & 983.1 & 31 & 102.3 & Reject \\
\hline & & & 01-JUN-90 & 2110.8 & 120 & 39.2 & Acocpt \\
\hline & & & O5-JUL-90 & 2650.4 & 34 & 66.1 & Acoept \\
\hline & & & 09-AUG-90 & 3200.4 & 35 & 65.5 & Acocpt \\
\hline & & & 23-NOV-90 & 5675.2 & 106 & 97.3 & Acoept \\
\hline & & & 14-DEC-90 & 6303.9 & 21 & 124.7 & Reject \\
\hline & & & 14FEB-91 & 7047.9 & 62 & 50 & Acoept \\
\hline & & & 18-MAR-91 & 8287 & 32 & 161.3 & Reject \\
\hline
\end{tabular}

TIME METER READINGS FOR THE ISSU ON CG 56

Since Elapsed Time Meter (ETM) data is not available for all ships, available data had to be used to automatically calculate elapsed time. In order to do this, calculate the percentage of calendar time that each unit was on for each ship which has recorded time meter data, then use all available ships' data to estimate unavailable ships' data. Equation (6) is used to estimate percentage time used for a single ship:

$$
\text { PERCENTAGE USE }=\frac{\sum_{i=2}^{n}\left[E T M_{1}-E_{T M_{i-1}}\right]}{24 \sum_{i=2}^{n}\left[D A T E_{1}-D A T E_{i-1}\right]}
$$

Where the restrictions of equations (7), (8) and (9) must be applied.

$$
\begin{aligned}
& \sum_{i=2}^{n}\left(E T M_{t}-E T M_{t-1}\right)>0 \\
& 24 \sum_{i=2}^{n}\left(D_{T} E_{i}-D_{T E E_{t-1}}\right) \geq \sum_{i=2}^{n}\left(E T M_{1}-E T M_{i-1}\right) \\
& \sum_{t=2}^{n}\left(D_{T} T E_{t}-D_{T} T E_{t-1}\right) \leq 120 \text { Days }
\end{aligned}
$$

The equation (7) eliminates meter readings where a meter appears to have "rolled back", the equation (8) ensures that time meter readings do not exceed calendar time, and the equation (9) ensures that the meter reading dates are not so far apart enough to mask anomalous readings. Note that the first reading was rejected due to the equation (9) and several other readings were rejected due to the equation (8).

For the data recorded in TABLE 2,

$$
\text { PERCENTAGE USAGE } E_{C G 5, J S S U}=63.45 \%
$$

Once the percentage used for all ships is calculated, an ordered list of all ships is constructed for statistical analysis, which is given in TABLE 3.

TABLE 3.

\begin{tabular}{||l|l|l|l|l|l|l|l||}
\hline No. & Range & Hull & x Used & No & Range & Hull & \% Used \\
\hline \hline 1 & 0 -5\% & FFG 42 & $0.6 \%$ & 25 & $40.1-45 \%$ & FFG 33 & $40.2 \%$ \\
\hline 2 & & FFG 7 & $1.6 \%$ & 26 & 45.1 -50\% & CG 59 & $45.2 \%$ \\
\hline 3 & & FFG 47 & $2.9 \%$ & 27 & & FFG 55 & $45.8 \%$ \\
\hline 4 & & FFG 48 & $4.6 \%$ & 28 & & FFG 32 & $49.3 \%$ \\
\hline 5 & $5.1-10 \%$ & FFG 54 & $5.3 \%$ & 29 & $50.1-55 \%$ & DD 980 & $51.6 \%$ \\
\hline 6 & & DD 964 & $7 \%$ & 30 & & FFG 37 & $53.5 \%$ \\
\hline 7 & & CG 61 & $9.2 \%$ & 31 & & CG 48 & $53.6 \%$ \\
\hline 8 & $10.1-15 \%$ & FFG 36 & $14.6 \%$ & 32 & & FFG 49 & $55 \%$ \\
\hline 9 & $15.1-20 \%$ & FFG 50 & $15.2 \%$ & 33 & $55.1-60 \%$ & FFG 43 & $56.5 \%$ \\
\hline 10 & & DD 974 & $15.7 \%$ & 34 & & FFG 45 & $59.3 \%$ \\
\hline 11 & & FFG 51 & $16.3 \%$ & 35 & $60.1-65 \%$ & DD 991 & $60.7 \%$ \\
\hline 12 & & FFG 52 & $16.4 \%$ & 36 & & FFG 41 & $62.6 \%$ \\
\hline 13 & & DD 965 & $17.5 \%$ & 37 & & CG 56 & $63.5 \%$ \\
\hline 14 & & FFG 57 & $20 \%$ & 38 & & CG 57 & $64.5 \%$ \\
\hline 15 & & FFG 13 & $20 \%$ & 39 & $65.1-70 \%$ & CG 50 & $65.7 \%$ \\
\hline 16 & $20.1-25 \%$ & DD 971 & $23.6 \%$ & 40 & & CG 60 & $67.7 \%$ \\
\hline 17 & & FFG 61 & $24.1 \%$ & 41 & & CG 53 & $68.3 \%$ \\
\hline 18 & & FFG 12 & $24.7 \%$ & 42 & $20.1-75 \%$ & FFG 40 & $71.1 \%$ \\
\hline 19 & $25.1-30 \%$ & CG 62 & $25.7 \%$ & 43 & & FFG 38 & $71.6 \%$ \\
\hline 20 & $30.1-35 \%$ & CG 51 & $32.9 \%$ & 44 & & CG 55 & $72.5 \%$ \\
\hline 21 & $35.1-40 \%$ & FFG 56 & $35.4 \%$ & 45 & $80.1-85 \%$ & DD 992 & $81.3 \%$ \\
\hline 22 & & CG 54 & $36.3 \%$ & 46 & $90.1-95 \%$ & FFG 8 & $91.2 \%$ \\
\hline 23 & & FFG 59 & $36.4 \%$ & 47 & $95.1-$ & CG 58 & $97.3 \%$ \\
\hline 24 & & DD 967 & $38.1 \%$ & 48 & & FFG 28 & $99.9 \%$ \\
\hline \hline
\end{tabular}

PERCENTAGE USAGE FOR UNIT 306 ISSU

The data in Table 3 is plotted on a frequency histogram by range in Figure 1. This is not an uniform distribution. Since this is a random distribution, a nonparametric approach must be used to estimate the percentage of use for the hulls which lack ETM data.

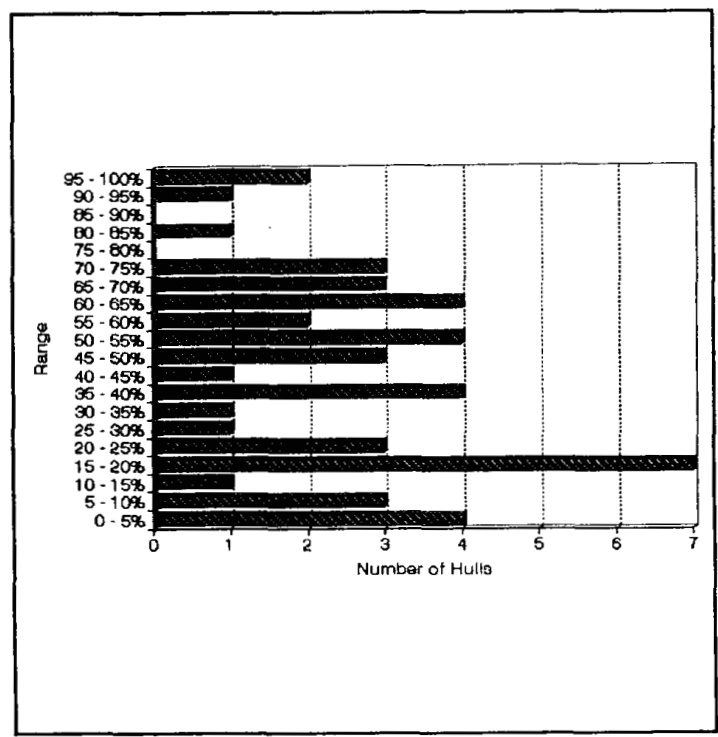

Figure 1. Percentage of Use Histogram for SA-2359 (ISSU) 
Using a nonparametric statistical technique, the median of the data TABLE 3 was estimated at $40.6 \%$. This median was tested using a two-sided Wilcoxon test with $80 \%$ sconfidence. The result of the Wilcoxon test was that the estimate of $40.6 \%$ was a very good estimate of the data.

Since actual data is always preferable to an estimate, time estimation for the whole fleet utilizes available data when available and an estimate for when actual data is not available:

$$
\begin{aligned}
\text { Total Time for ISSU } & =\sum_{i=1}^{43}(\text { Percent Used), (Calendar Time), + } \\
& \sum_{j \rightarrow 9}^{\infty}(.400) \text { (Calendar Time), }
\end{aligned}
$$

Where $\mathbf{n}=$ number of vessels which have an ISSU. Fortyeight is the number of ships for which have some time meter readings from which to form an estimate.

\section{SOME OBSERVATIONS FROM ESTIMATE}

A Practical Application for Using Percentage of Use Values:

Not only the SA-2359, but all the frequency histograms drawn for AN/SQQ-28(V) time distributions showed uneven distributions. This leads to two questions:

Why does this occur?

What may be learned from it?

It is believed that different ships use their systems for different percentages of the time because there are two diametrically opposed philosophies regarding leaving equipment on:

1) Leave the Equipment on all the time because the stress involved in energizing and deenergizing causes more failures than constant usage.

2) Turn the Equipment on only when needed to save energy or to reduce long term stress on the equipment.

The first philosophy is widely believed by the fleet and many system experts. It is believed that it was more dramatically true when systems which are dependant on vacuum tubes CRT tubes, and certain types of transistors. The questions which the type of data being constructed will be able to answer are:

1) Is there any statistical reason to adopt one philosophy over the other?

2) Are some types of equipment liable to fail more when energized continuously and others when energized only when needed?

3) Which philosophy should be used in which circumstance?

4) What is the best philosophy to use when the objective is mission readiness? Cost Minimization?

A simple regression analysis can be constructed comparing number of failures per year on a system to percentage of time the equipment is on. If there is regression, then number of failures can be estimated by percentage of time the equipment is on.

The regression analysis in question was performed on the units of the AN/SQQ-28(V), and no regression was found in any systems. It should be noted that there was over simplification used in constructing this model and this model needs more data to answer the questions posed more fully. For instance, since systems use different philosophies at different times, data should be broken down more granularly over the life of the equipment (In this analysis, only one "percentage-used" value [percentage of time equipment is on] was used for each ship). Failures must be broken down by failure type and failure mode for intelligible results (regression was performed on total number of failures).

The governing equation for this regression analysis is equation (12):

No. of Failures/year (mitimeded $)=\beta_{0}+\beta_{1}(\%$ of time on $)$

The data will be examined at finer granularity described above to yield more definitive answers but the regression analysis for the data obtained is provided in TABLE 4 to stimulate discussion.

TABLE 4.
\begin{tabular}{|l|c|c|c|c|}
\hline EQUIPMENT & $\beta_{4}$ & $\beta_{1}$ & $F$ & $\begin{array}{l}\text { Satistical Test } \\
\text { Value } f \text { (200ept } \\
\text { if F }>\text { at 90\% } \\
\text { s-0onfidenoc) }\end{array}$ \\
\hline AN/USQ-69V) & 0.1894 & 0.0066 & 0.000644 & 4.06 * \\
\hline ANJYS-1(V) & 0.1799 & 0.3582 & 1.8413 & 4.04 \\
\hline AN/UYK-20AX(V) & 0.6213 & 0.3233 & 0.2946 & 4.05 \\
\hline AN/USH-32(V) & 1.1524 & 4.9259 & 1.7307 & 4.05 \\
\hline TD-1307 (TCCU) & 0.2015 & 1.3874 & 1.498 & 4.04 \\
\hline SA-2359 (ISSU) & 0.3434 & 0.2065 & 0.2065 & 4.06 \\
\hline
\end{tabular}

REGRESSION FOR FAILURES PER YEAR AS A FUNCTION OF PERCENTAGE TIME

* It is believed that there was no regression because many different kinds of failures were lumped together. There are some kinds of failures which have positive regression (i.e. more likely to fail when system is on constantly) and some with negative regression (more likely to fail when system is turned on and off or energized only when needed). Therefore, with a test that lumps all failures together, one could find no regression when regression exists.

For more meaningful results, data can be divided into modes such as electrical failures, mechanical failures, wearout failures, quality failures and power related failures. Data should also be divided into kinds of parts failing such as electrical components (resistors, transistors, capacitors), power supplies, light bulbs, replacement items, etc. Individual data trends may reveal regression for particular failure modes or types of components. 


\section{REFERENCES}

1. J. M. Juran, F. M. Gyma, Juran's Quality Control Handbook, Fourth Edition, 1988, McGraw-Hill Book Company, pp 23.1 - 23.121.

2. R. V. Hogg, E. A. Tanis, Probability and Statistical Inference, Third Edition, 1988, Macmillan Publishing Company.

3. Maintenance Requirement Card EJX1, "Read and Record all Equipment Elapsed Time Meters".

4. S. R. Luke, AN/SQQ-28(V) Reliability Analysis, Naval Sea Combat Systems Engineering Station (not released for public information).

5. AN/SQQ-89(V) Time Meter Readings for Failure Analysis Database, Naval Sea Combat Systems Engineering Station, Norfolk, VA (not released for public information).

\section{BIOGRAPHY}

Stephen R. Luke, P.E., C.Q.E.

NUWC Detachment Norfolk, Code 33412

835 Philpotts Road

Norfolk, VA 23513-3199 USA
Mr. Luke is a registered professional engineer in the Commonwealth of Virginia. He received his bachelor's degree in Mechanical Engineering from Virginia Polytechnic Institute in 1983 and is presently pursuing a Master's Degree in Engineering Management at Old Dominion University. He has worked as a test engineer at Norfolk Naval Shipyard from 1978 to 1989 and as a reliability/quality engineer at Naval Undersea Warfare Center Detachment, Norfolk in Norfolk, Va from 1989 to present. Currently, he is the group leader of the RMA/QA group for the AN/SQQ-89 at Naval Undersea Warfare Center Detachment, Norfolk. He is a member of ASNE, IEEE (Reliability Society), and ASQC. He is also an ASQC Certified Quality Engineer.

Rajesh Sutariya

NUWC Detachment Norfolk, Code 33412

835 Philpotts Road

Norfolk, VA 23513-3199 USA

Mr. Sutariya is an Electrical Engineer at Naval Undersea Warfare Center Detachment, Norfolk. Mr. Sutariya received his bachelor's degree in Blectrical Engineering from Old Dominion University in 1990. Currently, Mr. Sutariya is a reliability/quality engineer at Naval Undersea Warfare Center Detachment, Norfolk in Norfolk, Va. Mr. Sutariya is a member of lEEE. 